$\begin{array}{rll}\text { Artvin Çoruh Üniversitesi } & \text { Artvin Coruh University } \\ \text { Orman Fakültesi Dergisi } & \text { Journal of Forestry Faculty } \\ \text { ISSN:2146-1880, e-ISSN: 2146-698X } & \text { ISSN:2146-1880, e-ISSN: 2146-698X } \\ \text { YII: 2015, Cilt: 16, Sayı:1, Sayfa: 55-64 } & \text { Year: 2015, Vol: 16, Issue: 1, Pages: 55-64 }\end{array}$

http://edergi.artvin.edu.tr

Araştırma makalesi

\title{
Tarım traktörleriyle bölmeden çıkarmada meydana gelen toprak ve fidan zararlarının araştırılması
}

\section{Investigation of soil and seedling damages from occurring in extraction with farm tractors}

\author{
Yılmaz TÜRK ${ }^{1}$, Selçuk GÜMÜş² \\ ${ }^{1}$ Düzce Üniversitesi, Orman Fakültesi, Orman Mühendisliği Bölümü \\ ${ }^{2}$ Karadeniz Teknik Üniversitesi, Orman Fakültesi, Orman Mühendisliği Bölümü
}

Özet

Bu çalışmanın amacı, odun hammaddesinin tarım traktörleriyle sürütme şeritleri üzerinde sürütülerek bölmeden çıkarılmasında oluşan toprak ile fidan zararlarının belirlenmesi ve meydana gelen bu çevresel zararları önleyebilme imkânlarının araştırılmasıdır. Balıklı Orman İşletme Şefliği'nde (Düzce-Gölyaka) eğimi \%0-33 arasında olan üretim alanları çalışma alanı olarak seçilmiştir. Çalışmada, belirlenen her bir sürütme şeridi $10 \mathrm{~m}$ aralıklarla örneklenmiştir. Çalışma alanında sürütme etkisinin olmadığı kontrol noktalarından, sürütme şeridine olan uzaklığı en az 25-30 m olmak üzere yine 10 m aralıklarla örnekler alınmıştır. Örnek alanlarda 0-5 cm ile 5-10 cm toprak derinlik kademesinde el penetrometresi kullanılarak toprak sıkışıklığı, sürütme şeritlerindeki toprak kayıpları ve fidan zararları ölçülmüştür. Çalışma sonucunda, sürütme şeritlerinde hektarda $703 \mathrm{~m}^{2}$ alanın toprak sıkışıklığına maruz kaldığı belirlenmiştir. Sürütme şeritlerinde devamlı sürütmeden dolayı farklı derinliklerde toprak aşınımı olmuş, hektarda 53.39 $\mathrm{m}^{3}$ (134009 ton) toprak kaybı tespit edilmiştir. Ayrıca sürütme şeritlerinin büyük bir bölümünde fidanların bulunmadığı, mevcut bireylerin de yatık, kırık ile sökülmüş olduğu ve hektarda 6432 adet fidanın zarar gördüğü belirlenmiştir.

Anahtar kelimeler: Bölmeden çıkarma, tarım traktörleri, toprak ve fidan zararları

Abstract

Aims of the study, environmental problems are determined at logs extracting with farm tractors skidding on skid trail and the soil and seedling damages prevention possibility are investigated. This direction aims to; the harvesting units with the ground slope of $0-33 \%$ were selected as study area located in Balıklı Forest Enterprise Chief (Düzce-Gölyaka). The study, the skid trails were sampled at $10 \mathrm{~m}$ intervals. Samples were taken again at $10 \mathrm{~m}$ intervals from the undisturbed area protected from skidding at least 25-30 m away from the skid trails. Soil compaction at the sample areas were taken was measured at 0-5 cm and 5-10 cm depths by using a hand penetrometer. Besides, soil loss and seedlings damage were measured on skid trails. Result of study, it was determined that soil compaction of $703 \mathrm{~m}^{2}$ per hectare in skid trails. Inasmuch as continuous skidding, soil erosion was determined different depths on samples from the skid trails, It was found that soil loss of $53.39 \mathrm{~m}^{3}$ (134009 ton) per hectare. Besides, there were not seedlings on a good part of skid trails, existing seedlings were lying, broken, and dismantled that were determined, it was found that residual damages on 6432 seedlings per hectare.

Key words: Extraction, farm tractors, soil and seedling damage

\section{GíRiş}

Ormancllıkta endüstriyel odun hammaddesinin (tomruklar, direkler ve sanayi odunları vb.) üretimi; genel itibariyle kesme, bölmeden çıkarma ve taşıma aşamalarından oluşmaktadır. Bu aşamaların yeri ve şekli organizasyona bağlı olarak değişebilmektedi (Özçamur 1981; FAO 1982; Dykstra and Heinrich 1996). Ülkemizde odun hammaddesi üretim aşamaları Orman
Genel Müdürlüğünce (OGM) yürütülmektedir. Orman işletmeleri ormanda üretilen odun hammaddesini ekosisteme zarar vermeyecek şekilde alarak piyasaya ulaştırır ve gelirlerinin büyük bir kısmını elde eder. Bu süreç içinde bölmeden çıkarma en önemli aşamayı oluşturur.

Bölmeden çıkarma aşaması, odun hammaddesi üretim aşamalarının en zor, pahalı ve çevresel zararı en fazla 
olan aşamasıdır. Ayrıca DPT (2007)'e göre Ülkemiz ormanlarının yaklaşık yarısı, eğimin \%44'ün üzerinde olduğu dağlık alanlarda yer alması da bu aşamayı olumsuz yönde etkileyen etmenlerdendir.

Endüstriyel odun hammaddesi üretim aşamalarından biri olan bölmeden çıkarma işlerinde teknik, ekonomik ve ekolojik etmenlere göre farklı araç ve yöntemler uygulanmaktadır. Endüstriyel odun hammaddesinin traktörler ile sürütme şeritlerinden sürütülerek, geçici istif yerlerine (rampaya) getirilmesi bu yöntemlerden bir tanesidir (Şekil 1). Sürütme şeritleri üretimden önce planlanarak geçki üzerindeki ağaçların temizlenmesiyle oluşturulan, üretim araçlarından $1 \mathrm{~m}$ daha geniş $(2,5-$ 3,5 m) olan geçici transport tesisleridir.

Ülkemizde bölmeden çıkarma çalışmalarında traktörlerin kullanımına yönelik yasal ve teknik bir mevzuat bulunmamaktadır. Bu nedenle sürütme çalışmaları orman işçilerinin deneyimlerine bağlı olarak düzensiz bir şekilde yürütülmektedir. Bundan dolayı da orman alanlarının birçok yerinde olumsuz çevresel etkilerin meydana gelmesinin yanında, zamansal ve ekonomik kayıplar da oluşabilmektedir.

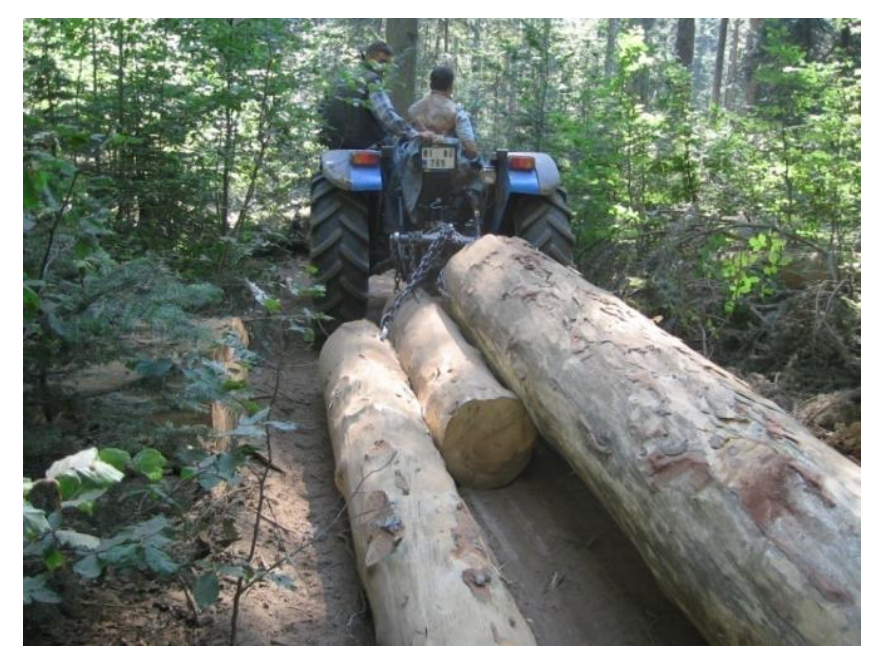

Şekil 1. Tarım traktörüyle sürütme şeridi üzerinde sürüterek bölmeden çıkarma

Ormanlardan yararlanma ile orman koruma yaklaşımı; ormancılık operasyonları ile ilgili kararların alınmasını zorlaştırmaktadır. Odun hammaddesi üretimi; toprakta, kalan meşcerede ve üretilen üründe farklı oranlarda zararlar oluşturmaktadır (Bayoğlu 1972; Gürtan 1975; Aykut 1984; Acar 1994). Endüstriyel odun hammaddesinin zemin üzerinde sürütülmesi sonucu oluşan çevresel zararlar; toprağın fiziksel özelliklerinde bozulma (sıkışma, gözenek hacminde azalma, sıkışmaya bağlı olarak su ve hava kapasitesinin azalması ve hacim ağırlığında artış, yüzeysel akış ve erozyonla toprak kaybı, toprak taşınması ve karışma), bitki gelişiminde gerileme ve tür çeşitliliğinde değişimler (bitki kök gelişiminin bozulan toprak özelliklerinden dolayı gerilemesi, besin maddesi alımının engellenmesi), toprak organik maddesi ve ölü örtüsünde humuslaşma ile mineralizasyonda toprak canlılarının yaşam şartları ve aktivitelerindeki etkilere bağlı olarak gerileme, toprakta denitrifikasyon yoluyla azot kayıpları olarak sıralanabilir (Erdaş 1993; Messina ve ark. 1997; Wang 1997; Bengtsson ve ark. 1998; Arocena 2000; Marshall 2000; Gilliam 2002; Buckley ve ark. 2003; Williamson ve Neilsen 2003; Godefroid ve Koedam 2004; Johnston ve Johnston 2004; Makineci ve ark. 2007).

Bu çalışmada tarım traktörleriyle sürütme şeritleri üzerinde sürüterek bölmeden çıkarmada meydana gelen toprak ve fidan zararlarını incelemek, meydana gelen bu çevresel zararları önleyebilme imkanlarını araştırmak, sürütme işlerinde bu çevre zararlarıyla ilgili kısıtlayıcı faktörleri belirlemek, sürütme sonucu saptanan toprak ve fidan zararlarını en alt düzeye indirmek, CBS ortamında sürütme şeritlerini planlayarak, mevcut durumla çevresel yönden karşılaştırmaktır.

\section{MATERYAL VE YÖNTEM}

Bu çalışma, Düzce ili, Gölyaka ilçesi, Balıklı Orman İşletme Şefliği'nin 48, 50, 51, 52, 53, 61, 63, 64, 66, 68, $69,74,75$ ve 76 numaralı bölmelerinde yapılmıştır (Şekil 2). Balıklı Orman İşletme Şefliği 40 38' 40" - 40ㅇ 42' 40" Kuzey enlemleri ile 30 57' 35" - 310 06' 45" Doğu boylamları arasında yer almaktadır. İşletme Şefliği'nin genel alanının tamamı ormanlık alanla kaplı ve büyüklüğü 5822 ha olup açıklık alan bulunmamaktadır. Ormanlık alanın 5469 ha'ı ağaçlı 
alandan, 353 ha'ı ise ağaçsız alandan (OT) oluşmaktadır. İklim genellikle yazları serin, kışları yağışlı ve soğuk geçmektedir. Bölgenin ortalama yıllık sıcaklığı 13,3 으, maksimum sıcaklığı 42,0 으 ve minimum sıcaklığı $-20,5$ oC'dir. Ortalama yıllık yağış $884,9 \mathrm{~mm}$ olup, nisbi nem oranı ise \% 76'dır (Anonim 2001). Çalışma alanı Göknar (Abies bornmulleriana Mattfeld) ve Kayın (Fagus orientalis Lipsky) karışık meşceresinden oluşmaktadır. Meşcereler 3 kapalı, orta ve kalın ağaçlık çağındadır. Çalışma alanının ortalama eğimi \%17 ve bakısı Güney-Doğu'dur. Endüstriyel odun hammaddesi, tarım traktörlerinin arkasına bağlanan zincirlerle ya da traktöre monteli vincin kablosuyla sürütme şeritleri üzerinde doğrudan sürütülerek bölmeden çıkarılmaktadır.

Endüstriyel odun hammaddesinin zemin üzerinde sürütülmesi sonucu oluşan çevresel zararların en önemli nedeni orman toprağında meydana gelen sıkışmadandır. Araştırma alanındaki sürütme şeritlerinde ve Kontrol noktalarında (KN) toprak sıkışıkığı ve kaybı durumunu ortaya koymak için ölçümler yapılmıştır.
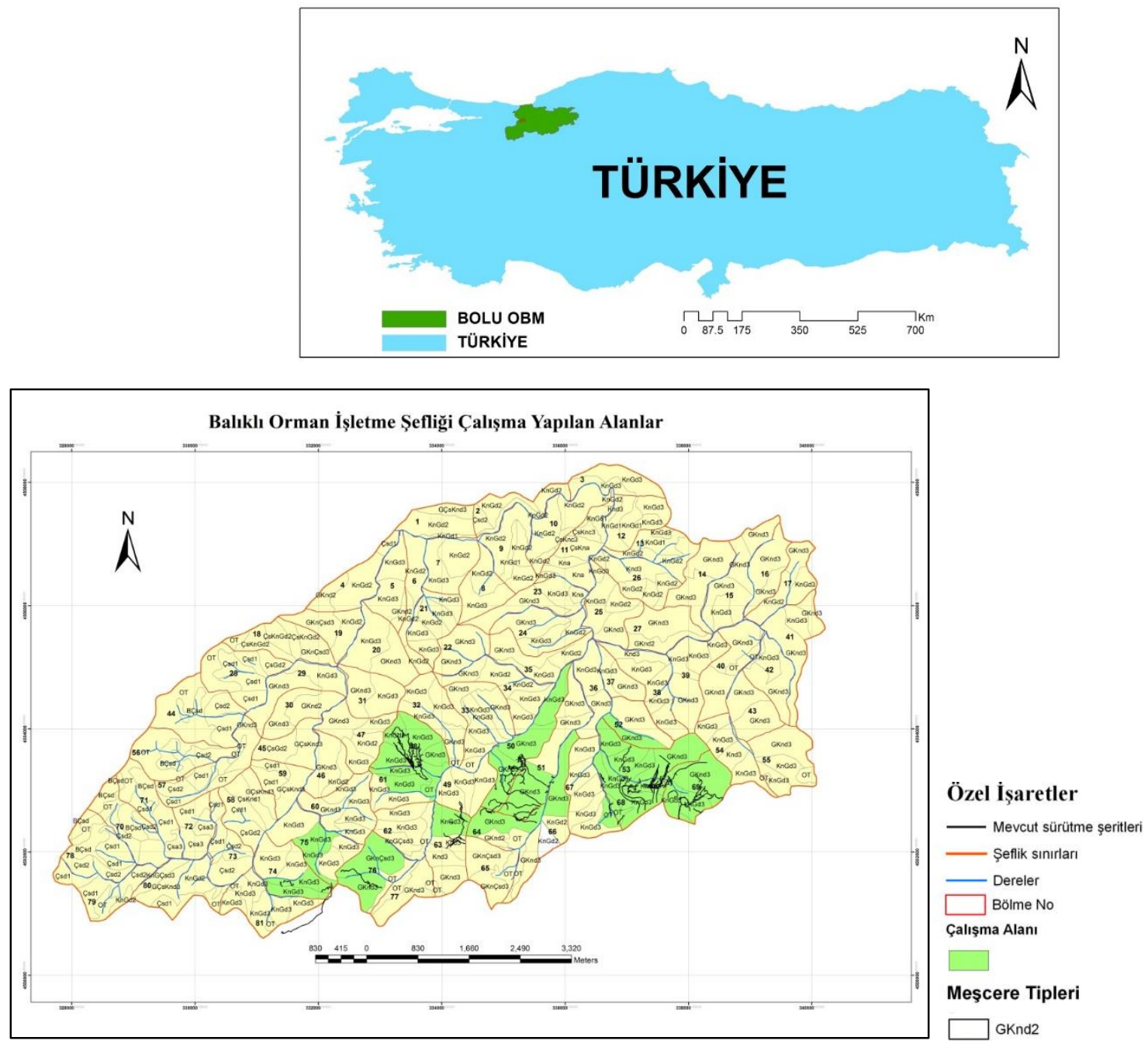

Şekil 2. Balıklı Orman İşletme Şefliğindeki çalışma alanları

Her bir sürütme şeridi $10 \mathrm{~m}$ aralıklarla örneklenmiştir (Şekil 3). Ayrıca çalışma alanında sürütme etkisinin olmadığı kontrol noktalarından, sürütme şeridine olan uzaklığı en az 25-30 m olmak üzere (kenar etkisini önlemek amacıyla en az bir ağaç boyu) yine $10 \mathrm{~m}$ aralıklarla örnekler alınmıştır. Sürütme şeridi 
üzerinden alınan örneklerde; toprak sıkışmasını belirlemek için iki farklı toprak derinliğinde $(0-5 \mathrm{~cm}$ ve 5-10 cm) el penetrometresi (toprak sıkışıklığı ölçer) kullanılarak sıkışıklık ölçülmüştür. (Karaöz 1989a; Karaöz 1989b; Karaöz 1992; Makineci ve ark. 2007). Ayrıca sürütme şeritlerinde oluşan toprak kayıpları da ölçülmüştür. Kontrol noktalarından alınan örneklerde; toprak sıkışıklığını belirlemek için örnek alanlardaki (ÖA) örneklemelere benzer şekilde iki farklı toprak derinliğinde el penetrometresi kullanılarak sıkışıklık ölçülmüştür.

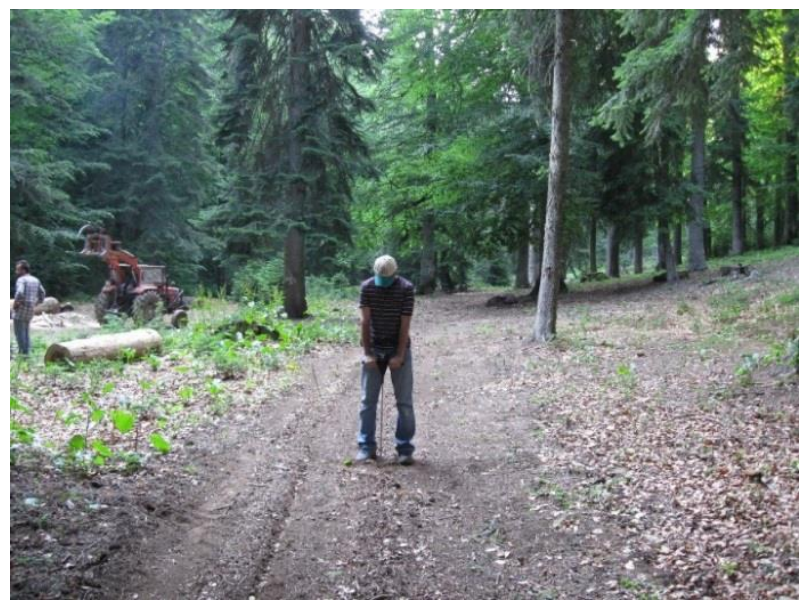

Şekil 3. Sürütme şeridinde el penetrometresiyle toprak sıkışıklığı ölçümü

Örnek alanda sürütme şeritlerinde oluşan toprak kaybını belirlemek için toprak aşınımı sonucu oluşan geometrik şekiller metreyle ölçülerek kesit alanları bulunmuş ve daha sonra sürütme şeridi uzunluğuyla çarpılarak toprak kaybı hacmi hesaplanmıştır (Türk 2006; Menemencioğlu 2006) (Şekil 4). Toprak kaybı değeri $\mathrm{m}^{3}$ ve ton birimlerinde verilmiş, ton birimini bulmada orman toprağının ortalama özgül ağırlığı 2510 ton/m³ olarak alınmıştır (Kara ve Bolat 2008).

Endüstriyel odun hammaddesinin zemin üzerinde sürütülmesi sonucu, sürütme şeritlerinin büyük çoğunluğunda fidanlar tamamen sökülüp uzaklaşmış, kalan fidanlar ise yatık ya da kırık durumda olduğu gözlemmiştir. Bu nedenle sürütme şeridi ile kontrol noktaları arasındaki fidan durumunu ortaya koymak için kontrol noktalarında $\mathrm{m}^{2}$ 'ye düşen fidan sayısı tespit edilmiş, hektardaki sürütme şeridi alanına oranlanmıştır.

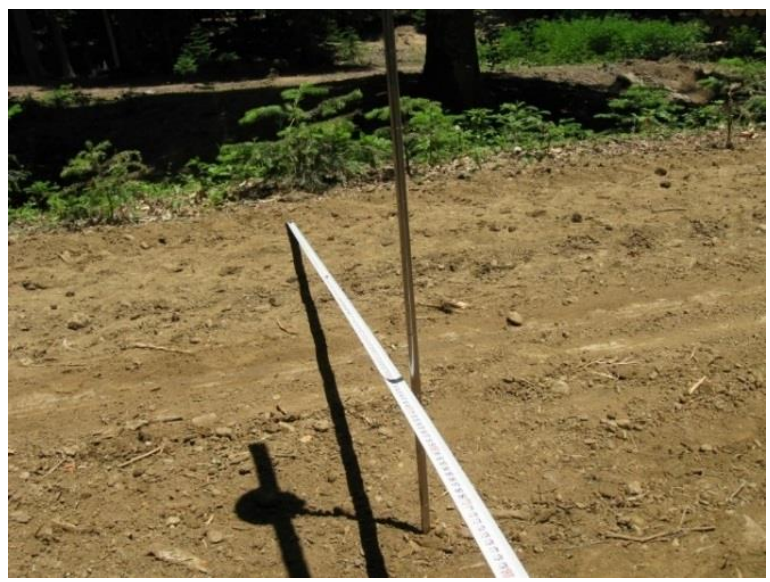

Şekil 4. Sürütme şeridinde oluşan toprak kaybının ölçülmesi

Çevre zararına en etkili olan değişkenleri (toprak kaybı, toprak sıkışıklığı, sürütme mesafesi, eğim ve şerit genişliği) belirlemek için istatistik yöntemlerden yararlanılmıştır. Bütün istatistiki analizler SPSS 13.0 programı ile gerçekleştirilmiştir. Çalışma kapsamında yapılan istatistiki değerlendirmeler;

- Ortalama ve sapmaların hesaplanması

- ÖA ile KN verileri ortalamalarının karşılaştırılması (Independent-Samples T-Testi)

- Değişkenler arası ilişkilerin araştırılması (Pearson Korelasyon Testi)

- Bağımlı değişkenlere ilişkin matematiksel modellerin belirlenmesi (Regresyon Analizi) şeklinde yürütülmüştür.

\section{BULGULAR VE TARTIŞMA}

\section{Toprak ve Fidan Zararlarına iliş̧kin Bulgular ve Tartışma}

Çalışma alanı sürütme şeritlerinde ölçüm yapılan örnek alanlara ve kontrol noktalarına ilişkin verilerin aritmetik ortalamaları, standart sapmaları, maksimumları ve minimumları Tablo 1'de verilmiştir. Mevcut sürütme şeritlerinin hektardaki ortalama uzunluğu $281 \mathrm{~m}$ ve ortalama alanı $703 \mathrm{~m}^{2}$ bulunmuştur. 
Tablo 1. Sürütme şeritlerinde ve KN'de ölçülen değişkenlere ilişkin veriler

\begin{tabular}{|c|c|c|c|c|c|}
\hline Değişken Adı & Birim & Minimum & Maksimum & Ortalama & Standart Sapma \\
\hline Sürütme şeridi genişliği & $\mathrm{m}$ & 1,62 & 3,03 & 2,43 & 0,25 \\
\hline Sürütme şeridi uzunluğu & $\mathrm{m}$ & 81 & 1418 & 389 & 281,8 \\
\hline $\begin{array}{l}\text { ÖA'da 0-5 cm derinliğindeki toprak } \\
\text { sıkışıklığı }\end{array}$ & psi & 179 & 780 & 386,04 & 129,2 \\
\hline $\begin{array}{l}\text { ÖA'da 5-10 cm derinliğindeki } \\
\text { toprak sıkışıklığı }\end{array}$ & psi & 213 & 800 & 537,19 & 156,6 \\
\hline $\begin{array}{l}\text { KN'da 0-5 cm derinliğindeki toprak } \\
\text { sıkışıkığı }\end{array}$ & psi & 50 & 250 & 128,46 & 43,55 \\
\hline $\begin{array}{l}\text { KN'da 5-10 cm derinliğindeki } \\
\text { toprak sıkışıklığı }\end{array}$ & psi & 74 & 338 & 173,99 & 53,55 \\
\hline KN'de ölçülen $\mathrm{m}^{2 ‘}$ deki fidan sayısı & adet & 1 & 17 & 9,15 & 3,62 \\
\hline Kaybolan toprak hacmi & $\mathrm{m}^{3} /$ ton & $2 / 5020$ & $530 / 1330300$ & $76 / 190760$ & 80,0 \\
\hline Kaybolan toprak hacmi (100 m için) & $\mathrm{m}^{3} /$ ton & $2 / 5020$ & $61 / 153110$ & $19 / 47690$ & 11,4 \\
\hline
\end{tabular}

Araştırma alanında endüstriyel odun hammaddesinin sürütme şeritlerinden sürütülerek orman dışına çıkarılması sonucu sürütme şeritlerinin farklı derinliklerde aşındığı belirlenmiştir. Çalışma alanında ortalama sürütme şeritleri yoğunluğu $281 \mathrm{~m} / \mathrm{ha}$ bulunmuştur. Buna göre; Tablo 1'de belirtien $100 \mathrm{~m}$ uzunluğundaki sürütme şeridinde ki ortalama toprak kaybı miktarı, sürütme şeridi yoğunluğuna oranlandığında hektarda $53.39 \mathrm{~m}^{3}$ (134009 ton) toprak kaybının olduğu belirlenmiştir.

Toprak kaybının olduğu alanlarda öncelikle erozyon hızlanmakta daha sonra oyuntu kanalları meydana gelerek toprak kayıpları oluşmakta, bu durum erozyonu tetiklemekte ve yer yer ana kaya açığa çıkmaktadır (Şekil 5). Sidle ve ark. (2004)'nın yapmış oldukları çalışmada, bölmeden çıkarma işlemleri sonucunda sürütme şeritleri üzerinde oluşan yüzeysel erozyon miktarını $272 \pm 20$ ton ha-1yıl-1 olarak tahmin etmişlerdir. Ayrıca daha dik eğimli (\%20<) arazideki sürütme şeritlerinde meydana gelen erozyon oranı (320 \pm 24 ton ha-1 yıl-1) düşük eğimli arazidekine (245264 ton ha-1 yıl-1) göre daha yüksek olduğunu belirtmişlerdir. Çalışmada elde edilen toprak kaybı verileri yıllık değerlendirme sonuçlarıdır. Ancak bu çalışmada elde edilen toprak kaybı değeri uzun süre sürütmenin yapıldığı sürütme şeritlerinden elde edilen değerlerdir. Bu nedenle arazide bulunan toprak kaybı değeri diğer çalışmaya göre daha yüksek bulunmuştur. Gürtan (1975); Yıldırım (1989); Tomasic (1996) ormanda kesilen ürünlerin orman dışına çıkarılması sırasında, özellikle eğimli bölgelerde orman toprağının zarar görebildiğini belirtmişlerdir. Bu zararlar genellikle erozyona elverişli oyuntular şeklinde gerçekleşmektedir. Orman arazisinde aşınma; bitki örtüsünün azlığı, eğim, taşıma ve yağış miktarı ile doğru orantılı olarak gelişmektedir. Görcelioğlu (2004) sürütme şeritlerinin planlanmasında belirleyici faktörlerden birinin bu yolların erozyona etkileri olduğunu ve toprakta tekerlek şeritleri oluşturan makinelerin meşcere toprağında sıkışmaya ve erozyona yol açtığını, bu nedenle bu makinelerin tavsiye edilmediğini savunmuştur. Hafif sürütme ekipmanı kullanılacaksa, sürütme yollarının hafif eğimli (yayvan) araziden geçirilmesini, sürütmede tarım traktörlerinden yararlanılacaksa yol eğimi \% 25'i aşmaması gerektiğini belirtmiştir. 

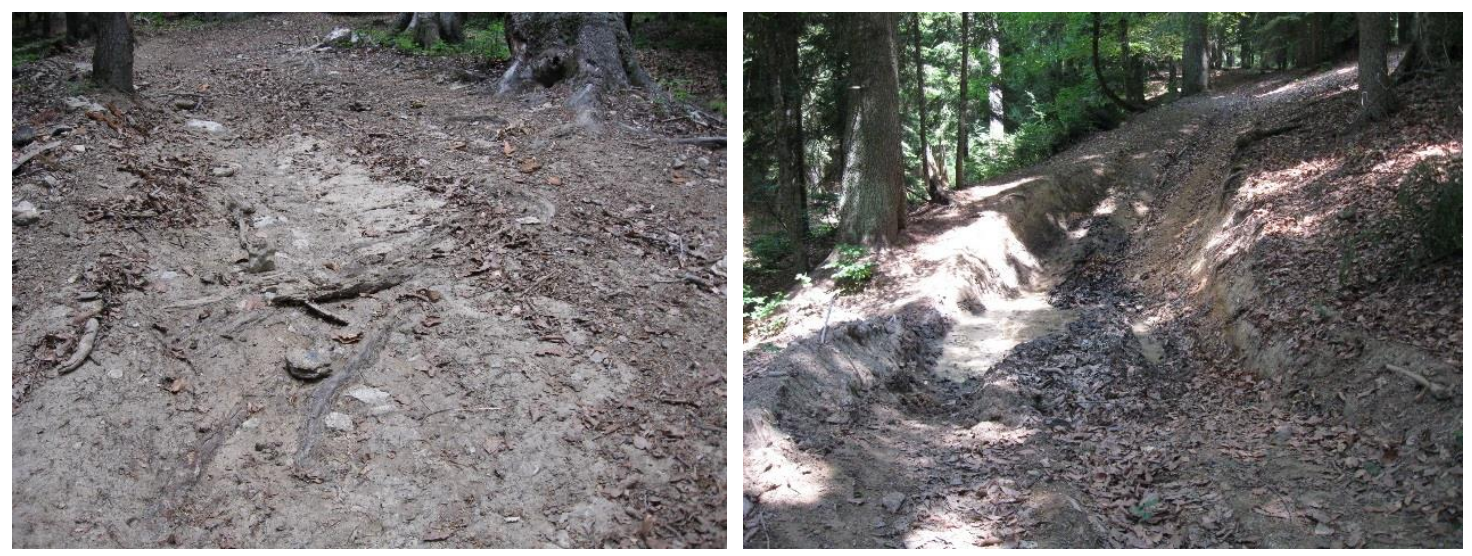

Şekil 5. Sürütme şeritleri üzerinde oluşan toprak aşınımı

Çalışma sonucunda, sürütme şeridindeki sıkışmanın kontrol noktasındakinden daha fazla olduğu, sürütme şeritlerinde hektarda $703 \mathrm{~m}^{2}$ alanın toprak sıkışıklığına maruz kaldığı belirlenmiştir. Makineci ve ark. (2007), korunan alan ve sürütme yolu (traktör yolu) arasında toprak sıkışıklığının önemli derecede fark gösterdiğini (sürütme yolundaki sıkışmanın korunan alandan daha fazla olduğu), sürütme şeritlerindeki ölü örtü ve diri örtü miktarının korunan alana göre önemli derecede azaldığını belirtmiştir.

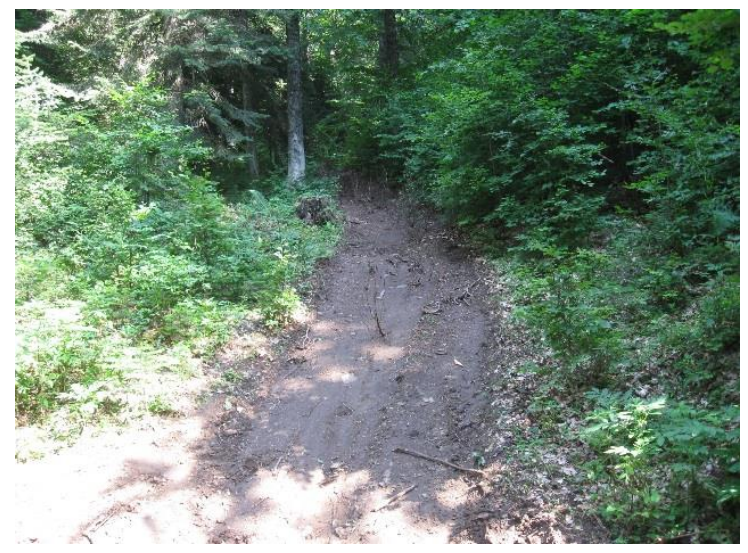

Şekil 6. Sürütme şeritleri üzerindeki yatık, kırık ve sökülmüş genç bireyler
Ayrıca sürütme şeritlerinin büyük bir bölümünde fidanların bulunmadığı, mevcut bireylerin de yatık, kırık ve sökülmüş olduğu gözlemmiştir. Bu nedenle sürütme şeridi ile kontrol noktaları arasındaki fidan durumunu ortaya koymak için kontrol noktalarında ölçümler yapılmış, m² $^{2}$ ye düşen fidan sayısı ortalama 9.15 adet olarak bulunmuştur. Bu sayı hektardaki mevcut sürütme şeridi ortalama alanına $\left(703 \mathrm{~m}^{2}\right)$ oranlandığında 6432 adet fidanın zarar gördüğü belirlenmiştir (Şekil 6).

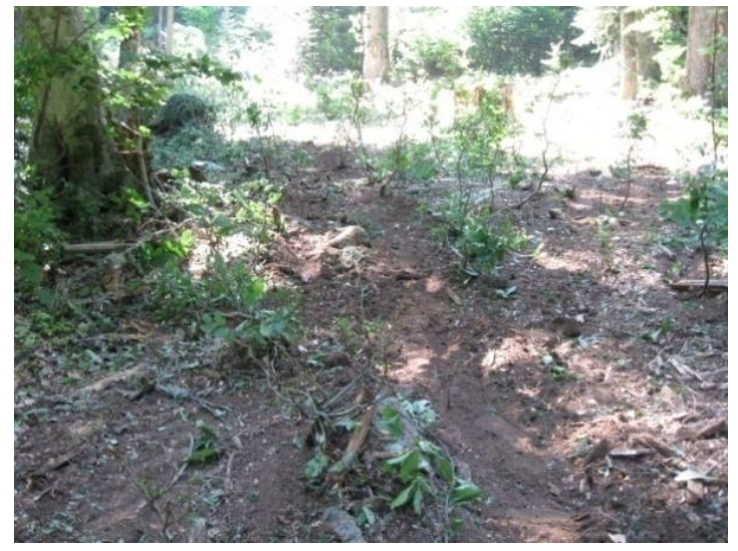

güven düzeyinde anlamlı bir ilişki olduğu belirlenmiştir (P>0.05). İstatistikî sonuçlara göre; 0-5 cm derinliğindeki toprak sıkışıkığı, 5-10 cm derinliğindeki toprak sıkışıklığı ile pozitif yönde, arazi eğimi ile negatif yönde \%95 güven düzeyinde anlamlı bir ilişki olduğu belirlenmiştir $(P>0.05)$. Ayrıca $5-10 \mathrm{~cm}$ derinliğindeki toprak sıkışıklığı; 0-5 cm toprak derinliğindeki sıkışıklık ve arazi eğimi ile pozitif yönde \%95 güven düzeyinde anlamlı bir ilişki olduğu belirlenmiştir ( $\mathrm{P}>0.05)$. 
Endüstriyel odun hammaddesinin tarım traktörleriyle sürütme şeritleri üzerinde sürütülerek bölmeden çıkarılması işleri sonucunda meydana gelen çevresel zararların ortaya konulması için oluşturulan bağımsız değişkenler kth (kaybolan toprak kaybı), ts05 (ÖA'da ölçülen 0-5 cm derinlikteki toprak sıkışıklığı) ve ts510 (ÖA'da ölçülen 5-10 cm derinlikteki toprak sıkışıklığı) olarak belirlenmiştir. Logaritmik dönüşüm uygulanarak normal dağılım göstermesi sağlanan kth eşitliği sürütme şeritleri üzerinde oluşan toprak kaybı değişkenini ifade etmektedir. Toprak kaybını etkileyen bütün değişkenler işleme sokulduğunda 1 numaralı eşitlik (lg10kth) en uygun eşitliği sağlamaktadır. Eşitlik $\% 95$ güven düzeyinde olup, $R^{2}$ değeri 0.714 ve standart hatası 0.210 'dur.

$k t h=-2,738+(0,001 \mathrm{ts} 05)+(1,133 \lg 10 \mathrm{sm})+(0,557 \mathrm{lg} 10 e)+(0,223 s \mathrm{~g})(1)$

Eşitlikte görüldüğü gibi toprak kaybı miktarı üzerinde 0-5 cm derinlikteki toprak sıkışıklığının (ts05), sürütme mesafesinin (Ig10sm), eğimin (Ig10e) ve şerit genişliğinin (şg) etkili olduğu, diğer değişkenlerin (zemin durumu, zemin sınıfı, 5-10 cm derinlikteki toprak sıkışıklığı) etkisinin istatistiki olarak önemli sayılmayacak düzeyde kaldığı belirlenmiştir. Eşitlik incelendiğinde, toprak kaybı ile değişkenler arasında doğru orantı olduğu belirlenmiştir.

Logaritmik dönüşümle oluşturulan ts05 eşitliği sürütme şeritleri üzerinde $0-5 \mathrm{~cm}$ toprak derinliğinden ölçülen toprak sıkışıklığı değişkenini ifade etmektedir. Toprak sıkışıklığını etkileyen değişkenler işleme sokulduğunda 2 numaralı eşitlik (Ig10ts05) en uygun eşitliği sağlamaktadır. Eşitlik \%95 güven düzeyinde olup, $R^{2}$ değeri 0.852 ve standart hatası $0.055^{\prime}$ tir.

$t s 05=2,229+(0,001 t s 510)+(-0,150 e)$

Toprak sıkışıklığı üzerinde, eşitlikteki $5-10 \mathrm{~cm}$ derinlikten ölçülen toprak sıkışıklığının (ts510) ve eğimin (Ig10e) etkili olduğu görülmüştür. Eşitlik incelendiğinde 0-5 cm toprak derinliğindeki sıkışıkla, 5$10 \mathrm{~cm}$ toprak derinliğindeki sıkışıklık arasında doğru orantı ve arazi eğimi arasında ise ters orantı olduğu belirlenmiştir.

Logaritmik dönüşümle oluşturulan ts510 eşitliği sürütme şeritleri üzerinde $5-10 \mathrm{~cm}$ derinlikten ölçülen toprak sıkışıklığı değişkenini vermektedir. Toprak sıkışıklığını etkileyen bütün değişkenler işleme sokulduğunda 3 numaralı eşitlik (sqrt ts510) en uygun eşitliği sağlamaktadır. Eşitlik \%95 güven düzeyinde olup, $R^{2}$ değeri 0.862 ve standart hatası 1.288 'dir.

$t s 510=-38,764+(9,673 \ln t s 05)+(3,527 e)$

Eşitlik incelendiğinde; $5-10 \mathrm{~cm}$ toprak derinliğindeki sıkışıkla, 0-5 cm toprak derinliğindeki sıkışıkık ve eğim arasında doğru orantı olduğu belirlenmiştir.

\section{Sürütmede Sürütme Şeritlerinin Planlanmasına Ait Bulgular ve Tartışma}

CBS ortamında, çalışmanın yapıldığı alan için sürütme şeritleri yeniden planlanmış ve mevcut durumla çevresel yönden karşılaştırılmıştır. Şekil 7'de planlanan sürütme şeritleri ağ haritası gösterilmektedir. Haritada her bir sürütme şeridi arasındaki mesafe yaklaşık olarak $50 \mathrm{~m}$ (iki ağaç boyu) olacak şekilde ve orman yoluna 35o-45o açıyla bağlanacak şekilde planlanmıştır.

Sürütme şeritlerinin planlanması sayesinde aynı işletmeye açma oranıyla ortalama sürütme şeritleri yoğunluğu hektarda $94 \mathrm{~m}$ ve kapladığı alan $236 \mathrm{~m}^{2}$ azalmış, gereksiz alan işgali engellenmiştir. Ayrıca sürütme şeritleri ağının planlanmasıyla üretim alanında, hektarda $236 \mathrm{~m}^{2}$ alanın toprak sıkışıklığına maruz kalması, hektarda $17,86 \mathrm{~m}^{3}$ (44829 ton) toprak kaybının olması ve hektarda 2159 adet fidanın bölmeden çıkarma sonucunda zarar görmesi gibi olumsuz faktörler önlenmiştir. Yapılan çalışmalarda, üretimden önce, hasat zararlarını azaltıcı transportta, etkili orman yolları planı ve en uygun sürütme şeridi ağlarının topoğrafik haritalarda bulunması ile sürütme şeritlerinin kesimden önce iyi bir şekilde planlanması ve araziye aplike edilmesi gerektiği ifade edilmiştir (Sist 1997; Adams 1998; Anonim 2005). 


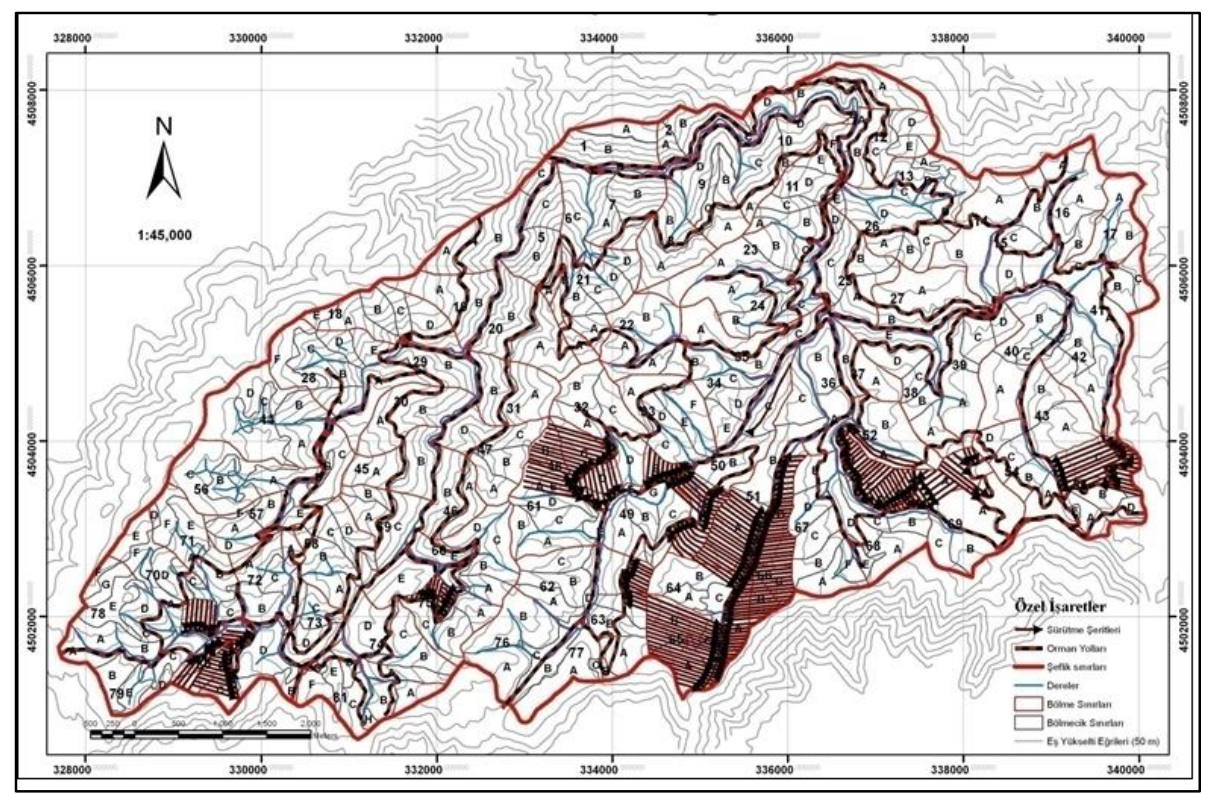

Şekil 7. Çalışma alanı sürütme şeritleri ağ haritası

\section{SONUÇ VE ÖNERILER}

Sürütme şeritleri planlanmadan endüstriyel odun hammaddesinin yükleme yerlerine sürütülerek getirilmesi yerine, olumsuz çevre etkileri minimize edilerek, sürütme şeritleri planlanmıştır. Sürütme zararlarını etkileyen faktörlerin model katsayıları belirlenmiştir.

Çalışmada, sürütme şeritlerinde hektarda $703 \mathrm{~m} 2$ alanın toprak sıkışıklığına maruz kaldığı ve sürütme şeritlerinde doğal alana göre daha fazla sıkışıklık olduğu tespit edilmiştir. Sürütme şeritlerinde devamlı sürütmeden dolayı farklı derinliklerde toprak aşınımı olmuş, hektarda 53.39 m3 (134009 ton) toprak kaybı tespit edilmiştir. Ayrıca sürütme şeritlerinin büyük bir bölümünde fidanların bulunmadığı, mevcut bireylerin de yatık, kırık ya da sökülmüş olduğu ve hektarda 6432 adet fidanın zarar gördüğü belirlenmiştir. Ayrıca sürütme şeritlerinin yoğunluğu arttıkça daha fazla alana girilmiş ve fidan zararları daha da artmıştır.

Mevcut durumda ortalama sürütme şeritleri yoğunluğu $281 \mathrm{~m} /$ ha iken sürütme şeritlerinin planlanmasıyla ortalama sürütme şeritleri yoğunluğu 187 m/ha'a düşmüş, gereksiz alan işgali engellenmiştir.
Sürütme şeritleri ağının planlanmasıyla üretim alanında, hektarda $236 \mathrm{~m} 2$ alanın toprak sıkışıklığına maruz kalması, hektarda 17.86 m3 (44829 ton) toprak kaybının olması ve hektarda 2159 adet fidanın bölmeden çıkarma sonucunda zarar görmesi gibi olumsuz faktörler önlenmiştir.

Bu çalışmada tarım traktörleriyle bölmeden çıkarmada bazı çevresel zararlar (toprak sıkışıklığı, toprak kaybı, meşceredeki fidan zararları) tespit edilmiştir. Diğer çevresel zararların tespiti için daha ayrıntılı çalışmalar yapılmalıdır.

Orman toprağında meydana gelen bozulmaları en aza indirmede sürütme şeritlerine örtülen yonga (cipper) ve dal-yaprak gibi kesim artıklarının (slash) durumu değerlendirilmelidir.

Mikro transport planlaması uygulamaya aktarılmalı ve sürütme şeritleri ağı mikro transport planına dâhil edilmelidir.

Endüstriyel odun hammaddesinin bölmeden çıkarılmasında, sürütücü operatörünün iş eğitimi alması ile üretim sonrası oluşan olumsuzlukların etkileri azaltılabilir ve iş verimi de artabilir. 


\section{TEŞEKKÜR}

Bu çalışma, Karadeniz Teknik Üniversitesi Araştırma Projeleri Yönetim Birimi tarafından 2008.113.001.3 Kod No'lu Proje kapsamında desteklenmiştir. Birim çalışanlarına teşekkürlerimizi sunarız.

\section{KAYNAKLAR}

Acar HH (1994) Ormancılıkta Transport Planları ve Dağlık Arazide Orman Transport Planlarının Oluşturulması, Yayınlanmamış Doktora Tezi, K.T.Ü., Fen Bilimleri Enstitüsü, 150 s., Trabzon.

Adams PW (1998) Soil Compaction on Woodland Properties. The Woodland Workbook Forest Protection, Oregon, ABD.

Anonim, 2005. Northeast Implement Corp. Farmi Tree Harvesting Method. 6p.

Arocena JM (2000) Cations in Solution from Forest Soils Subjected to Forest Flor Removal and Compaction Treatments. Forest Ecology and Management 133, 71-80.

Aykut T (1984) Orman Ürünleri Taşımacılığında Araç ve Teknikler, i.ü. Orman Fakültesi, İstanbul Yayınları No. 3246/370, 100.

Bayoğlu S (1972) Türkiye'de Orman Nakliyatı ve Geliştirilmesi İmkanları Üzerine Bir Etüd, i.ü. Orman Fakültesi, İstanbul, 1747/185, 73.

Bengtsson J H, Lundkvist P, Saetre B, Sohlenius ve B Solbreck (1998) Effects of Organic Matter Removal on the Soil Food Web: Forestry Practices Meet Ecological Theory. Applied Soil Ecology 9: 137-143.

Buckley D S, Crow TR, Nauertz E A, and Schulz K E (2003). Influence of Skid Trails and Haul Roads on Understory Plant Richness and Composition in Managed Forest Landscapes in Upper Michigan, USA. Forest Ecology and Management, 175, 509-20.

Devlet Planlama Teşkilatı (DTP) (2007). Dokuzuncu Beş Yıllık Kalkınma Planı Ormancılık Özel İhtisas Komisyonu Raporu, Ankara, $10 \mathrm{~s}$.

Dykstra DP ve Heinrich R (1996). FAO Model Code of Forest Harvesting Practice, FAO Publacitions, Rome, $85 \mathrm{p}$

Erdaş O (1993) Bölmeden Çıkarma Sırasında Traktör Kullanımının Orman Toprağının Mekanik Özelliklerine Etkisi ve Bunun Biyolojik Sonuçları. Tübitak Doğa Tarım ve Ormancılık Dergisi, $17(1)$.

FAO (1982) Basic Technology in Forest Operations, FAO Forest Paper, Rome, 33.

Gilliam F S (2002) Effects of Harvesting on Herbaceous Layer Diversity of a Central Appalachian Hardwood Forest in West Virginia, USA. Forest Ecology and Management, 155:33-43.

Godefrold S ve Koedam N (2004) The impact of Forest Paths upon Adjacent Vegetation: Effects of the Paths Surfacing Material on the Species Composition and Soil Compaction. Biological Conservation, 119:405-19.
Görcelioğlu E (2004) Orman Yolları-Erozyon illişkileri, i..Ü. Orman Fakültesi. Yay. No: 476, İstanbul.

Gürtan H (1975) Dağlık ve Sarp Arazili Ormanlarda Kesim ve Bölmeden Çıkarma İşlemlerinde Uğranılan Kayıpların Saptanması ve $\mathrm{Bu}$ İşlerin Rasyonalizasyonu Üzerine Araştırmalar, Tübitak Yayın No: 250, Proje No: Toag-81, Ankara.

Johnston F M ve Johnston SW (2004) Impacts of Road Disturbance on Soil Properties and Exotic Plant Occurrence in Subalpine Areas of Australian Alps. Arctic Antarctic and Alpine Research, 36(2): 201-7.

Kara Ö ve Bolat i (2008) Bartın İli Orman ve Tarım Topraklarının Mikrobiyal Biyokütle Karbon ( $\mathrm{Cmic}$ ) ve Azot (Nmic) İçerikleri, Ekoloji Dergisi, 18, 69, 32-40.

Karaöz O (1989a) Laboratory analyze methods of some physical soil properties related to water holding capacity. Review of the Faculty of Forestry, University of Istanbul, 39, B2, 133-44.

Karaöz O (1989b) Analyze Methods of Some Chemical Soil Properties $(\mathrm{pH}$, carbonates, salinity, organic matter, total nitrogen, available phosphorus). Review of the Faculty of Forestry, University of Istanbul, 39, B3, 64-82.

Makineci E, Demir M ve Yılmaz E (2007) Odun Üretimi ve Sürütme Çalışmalarının Orman Ekosistemine Ekolojik Etkileri. Proceedings of International Symposium Bottlenecks, Solutions. And Priorities in the Context of Functions of Forest Resource, 868-878 p., İstanbul.

Menemencioğlu K (2006) Ilgaz - Devrez Orman İşletme Şefliği'nde Coğrafi Bilgi Sistemi (CBS) Yardımıyla Orman Hasat Zararlarını Azaltıcı Transport Planlaması. A.İ.B.Ü. Ormancılık Dergisi, 2,1, Düzce.

Marshall V G (2000) Impacts of Forest Harvesting on Biological Processes in Northern Forest Soils. Forest Ecology and Management,133: 43-60.

Messına M G, Schoenholtz S H, Lowe MW, Wang Z, Gunter D K, Londo A J (1997), Initial responses of woody vegetation, water quality, and soils to harvesting intensity in a Texas Bottomland hardwood ecosystem. Forest Ecology and Management, 90:201-15.

Özçamur M (1981) Bölmeden Çıkarmada Çeşitli Makinelerin Zaman Verim ve Masraf Yönünden Araştırılması, Trabzon, 132, 14.

Sidle R C, Sasaki S, Otsuki M, Noguchi S, Nik AR (2004) Sediment Pathways in a Tropical Forest: Effects of Logging Roads and Skid Trails, Hydrologıcal Processes, 18, 703-720.

Sist P (1997) Effects of Logging on Forest Soil Physical Properties in Eastern Amazonia. Forest Harvesting Bulletin (March). Volume 7, No: 1 .

Yıldırım M (1989) Ormancılık İş Bilgisi, i..ü. Orman Fakültesi Yayın No: 3555/404, İstanbul.

Tomasic Z (1996) Soil Erosion on Several Longitudinal Slops of a Skid Trail over a Four-Year Period (1992-1996). Proceedings of The Seminar on Environmentally Sound Forest Roads and Wood Transport, 322-334p., June 1996, Sinaia, Romania. 
Tarım traktörleriyle bölmeden çıkarmada meydana gelen toprak ve fidan zararlarının araştırılması

Türk Y (2006) Düzce'de Orman Yollarında Toprak Kaybı Sorunlarının Araştırılması, Yayınlanmamış Yüksek Lisans Tezi, A.i.B.Ü., Fen Bilimleri Enstitüsü, Düzce, $43 \mathrm{~s}$.

Wang $L$ (1997) Assessment of animal skidding and ground machine skidding under mountain conditions. Journal of Forest Engineering, 8(2):57-64.
Williamson J R, Neilsen WA (2003) The effect of soil compaction, profile disturbance and fertilizer application o $\mathrm{n}$ the growth of eucalyptus seedlings in two glasshouse studies. Soil \& Tillage Research, 71:95-107.

Yıldırım M (1989) Hasat İşlerinde Sınırlayıcı Faktörler, i.ü. Orman Fak. Dergisi, 39, 4. 